\title{
Incorporation of $\alpha$-Amylase Enzyme and a Bioactive Filler into Hydrophilic, Partially Degradable, and Bioactive Cements (HDBCs) as a New Approach To Tailor Simultaneously Their Degradation and Bioactive Behavior
}

\author{
Luciano F. Boesel, ${ }^{*}$ Helena S. Azevedo, and Rui L. Reis \\ 3B's Research Group-Biomaterials, Biodegradables and Biomimetics, University of Minho, Campus of \\ Gualtar, 4710-057, Braga, Portugal and Department of Polymer Engineering, University of Minho, Campus \\ of Azurem, 4800-058, Guimarães, Portugal
}

Received April 20, 2006; Revised Manuscript Received June 23, 2006

\begin{abstract}
Hydrophilic, partially degradable, and bioactive cements (HDBCs) are starch-containing cements intended to degrade partially in the human body and, in so doing, allow for bone ingrowth inside the pores formed during degradation. Therefore, the study of degradation and bioactivity behavior was performed to assess the suitability of the current HDBCs formulations to achieve those aims. The degradation profile of HDBCs was studied under different conditions, including incubation in phosphate-buffered saline (PBS) and PBS supplemented with $\alpha$-amylase at different concentrations. Thermostable $\alpha$-amylase was also added to some formulations to allow control of the degradation rate and its extent. In a second stage the simultaneous phenomena of enzymatic degradation and bioactivity (both in vitro) was studied. We observed that the degradation of starch present in HDBCs can be easily controlled by the amount of $\alpha$-amylase added to the cement and high values of degradation may be achieved if high enough quantities of enzyme are incorporated. However, the maximum degradation extent is much more dependent on the total amount of starch present in the formulation than on the amount of enzyme added to it: for full pore connectivity, the amount of starch should be higher than the percolation threshold for a 3D specimen. Nonetheless, calcium phosphate was able to nucleate and spread in inner pores of the cement, formed due to degradation, if they were interconnected. For a more thorough covering of the pores with calcium phosphates the amount of starch present in HDBCs should be increased to be higher than the percolation threshold.
\end{abstract}

\section{Introduction}

Acrylic bone cements were developed for holding a femoral prosthesis in place and transferring the load received by the prosthesis to the bone. Although they adequately perform such function and cemented prosthesis present a survival rate of $82 \%$ after 17 years of implantation, ${ }^{1}$ in approximately $72 \%$ of the cases $^{1}$ the reason for failure is the aseptic loosening of the two interfaces (prosthesis-cement and cement-bone). The bonecement interface can be influenced by the toxicity of the monomer, bone necrosis due to the polymerization heat, inherent weakness of the cement, and presence of blood and tissue debris mixed during surgery. ${ }^{2}$ The most employed method to increase the strength of the interface is promoting the bone growth on the surface of the cement. In the past, this property has been achieved by incorporation of bone particles, ${ }^{3,4}$ growth hormones, ${ }^{5,6}$ bioactive glasses ${ }^{7}$ or glass - ceramics,${ }^{8,9}$ and hydroxylapatite (HA). ${ }^{10-12}$ The last three are the most promising materials, since they not only impart a bioactive behavior to the cements but also improve the mechanical properties of the material, acting as reinforcing fillers.

However, this approach still presents some problems. First, the contact with bone is totally dependent on the surface distribution of the bioactive fillers since only the particles at the surface are available to the bone. If the number of particles exposed to the bone is low, bone growth will be slow and/or the interface will not be reinforced. As Shinzato et al. ${ }^{13}$ showed,

* To whom correspondence should be addressed. E-mail: 1fboesel@ dep.uminho.pt. the detaching failure load (between cement and bone) can be eight times higher for an abraded surface (where the bioactive particles were intentionally exposed) compared to a normally cured surface. Second, the affinity between bone and cement decreased markedly in load-bearing sites due to mechanical stress or micromotion at the interface: the length of bone in direct contact with cement decreased almost five times when the cement was implanted in load-bearing sites. ${ }^{9,14}$

Therefore, other methods should be developed to create a stronger, more stable, and longer lasting interface between bone and cement. One alternative would be to promote the growth of bone not only in the surface but also in the interior of the cement. This could be achieved if a partially degradable cement can be prepared: the gradual degradation of the degradable component would generate pores and voids that could be filled by bone, growing due to the bioactive character imparted by the bioactive fillers. In that sense, the bone cement could be considered an in situ forming scaffold: immediately after implantation the cement is a dense construct, but as time increases it becomes more and more porous, as a typical biodegradable scaffold. ${ }^{15}$ One important difference is that while the latter are designed to be fully biodegradable, these cements will only degrade partially.

Recently, we developed a novel class of acrylic-based bone cements: the hydrophilic, partially degradable, and bioactive cements (HDBCs). They contain a hydrogel-forming monomer (2-hydroxyethyl methacrylate, HEMA) in the liquid component of the typical bone cement formulation, partially substituted for methyl methacrylate (MMA) in order to adjust the mechanical 
and swelling properties of the system. Therefore, the key characteristics of the hydrophobic, acrylic cements, such as fast polymerization rate, injectability, and high mechanical properties, are maintained, and the advantages of hydrogels-good compatibility with body fluids and tissues, improved release behavior of drugs, easier bioactivity, ${ }^{16}$ and others - are added. These hydrophilic bone cements also incorporate a starch-based blend that can degrade in the body and has already been studied for a range of biomedical applications such as scaffolds for tissue engineering, ${ }^{17,18}$ systems for drug delivery, ${ }^{19}$ hydrogels,${ }^{20,21}$ and proposed for bone replacement and regeneration applications. ${ }^{22,23}$ Previous reports have shown that the swelling kinetics of HDBCs depends on the $\mathrm{pH}$ of the surrounding medium, ${ }^{24}$ the amount of residual monomer is very low $(<1 \mathrm{~mol} \%),{ }^{25}$ and the molar ratio of monomers used determined the swelling kinetics and extent. ${ }^{26}$ Our preliminary degradation results did show that these HDBCs degrade when formulated with $\alpha$-amylase, which catalyzes the degradation of starch. ${ }^{27}$ Addition of enzymes to control the degradation of materials is beneficial because enzyme activity can be regulated by environmental conditions (e.g., pH, temperature, presence of metal ions or other substances, etc.) and the degradation kinetics can be adjusted by the amount of encapsulated enzyme into the matrix. Other starch-based formulations have been prepared containing encapsulated $\alpha$-amylase to develop enzymatically controlled drug delivery systems..$^{28-31}$ Goldbart et al. ${ }^{28}$ developed an enzymatically controlled responsive drug delivery system consisting of a starch-based tablet incorporating a nonactive $\alpha$-amylase and a protein. The enzyme reactivation was made by the presence of calcium ions, which causes tablet degradation and concomitant release of the protein. Similarly, Dumoulin et al. ${ }^{30}$ incorporated $\alpha$-amylase into cross-linked amylose tablets in order to modulate the release kinetics of drugs with limited solubility. Incorporated enzyme was more effective than enzyme present in the solution, even at high amounts.

Our aim, in this work, was to study in greater detail the degradation phenomena occurring inside these cements and the possibility, or not, of promoting simultaneous degradation/ bioactivity. It was divided in three stages: (a) study of the degradation of HDBCs in simulated physiological solutions containing $\alpha$-amylase, (b) incorporation of $\alpha$-amylase in the cement formulation and study of its effects, and (c) evaluation of the simultaneous bioactivity/degradation phenomena in a simulated body fluid (SBF).

\section{Materials and Methods}

2.1. Preparation of the Formulations and Solutions. Cement specimens were prepared by adding the solid component to the liquid component. The solid was constituted of a blend of corn starch/cellulose acetate $50 / 50 \mathrm{wt} \%$ (SCA) and, in some formulations, by the bioactive glass Bioglass 45S5 (NovaMin Technology Inc., Florida). The glass had particle sizes of $4.880 \mu \mathrm{m}$ and a surface area of $0.0571 \mathrm{~m}^{2} / \mathrm{g}$. The polymer particles were smaller than $125 \mu \mathrm{m}$. The liquid was constituted of 2-hydroxyethyl methacrylate (HEMA), which was used as received. In one formulation the liquid was a mixture of HEMA and methyl methacrylate (MMA) at a molar ratio of 1/2 (HEMA/MMA). Benzoyl peroxide powder (BPO) was used as the polymerization initiator at a molar concentration of 0.0072 with respect to the monomer amount (that is, $0.72 \mathrm{wt} \%$ of the solid). Dimethyl-p-toluidine (DMT) was used as the activator of the initiator at a molar concentration of 0.67 with respect to the BPO amount (that is, $0.57 \mathrm{vol} \%$ of the liquid). The solid/liquid ratio employed was $65 / 35$, and the concentration of the glass, when used, was fixed at $32.5 \mathrm{wt} \%$ of the total mass (that is, 50 wt $\%$ of the solid component). Water (or thermostable enzyme, please
Table 1: Description of the Cement Formulations Prepared in This Study

\begin{tabular}{|c|c|c|}
\hline code & description & use \\
\hline $\mathrm{COO}$ & base formulation, control & all tests \\
\hline CMO & $\begin{array}{l}\text { C00 containing MMA in } \\
\text { the liquid component. }\end{array}$ & \\
\hline $\mathrm{C} 10$ & $\mathrm{C} 00+0.10 \mathrm{~mL}$ water & degradation tests \\
\hline S05 & $\mathrm{C} 00+875 \mathrm{LU}_{\mathrm{taa}} / \mathrm{g}_{\mathrm{st}}{ }^{a}$ & degradation tests \\
\hline S10 & $\mathrm{C} 00+1750 \mathrm{LU}_{\mathrm{taa}} / \mathrm{g}_{\mathrm{st}}$ & degradation tests \\
\hline S50 & $\mathrm{C} 00+8750 \mathrm{LU}_{\mathrm{taa}} / \mathrm{g}_{\mathrm{st}}$ & degradation tests \\
\hline SM5 & $\mathrm{CMO}+875 \mathrm{LU}_{\mathrm{taa}} / \mathrm{g}_{\mathrm{st}}$ & degradation tests \\
\hline $\mathrm{BCO}$ & $\begin{array}{l}\text { Co0 containing } 32.5 \mathrm{wt} \% \\
\text { of bioactive glass }\end{array}$ & degradation/bioactivity tests \\
\hline S15 & $\mathrm{C} 00+1592 \mathrm{LU}_{\mathrm{taa}} / \mathrm{g}_{\mathrm{st}}$ & degradation/bioactivity tests \\
\hline B15 & $\mathrm{BCO}+1592 \mathrm{LU}_{\text {taa }} / \mathrm{g}_{\mathrm{st}}$ & degradation/bioactivity tests \\
\hline B30 & $\mathrm{BCO}+3185 \mathrm{LU}_{\text {taa }} / \mathrm{g}_{\mathrm{st}}$ & degradation/bioactivity tests \\
\hline
\end{tabular}

${ }^{a} \mathrm{LU}_{\text {taa }} / \mathrm{g}_{\mathrm{st}}=$ liquefon units of thermostable $\alpha$-amylase by mass $(\mathrm{g})$ of starch in the formulation. One LU is the measure of digestion time required to produce a color change with iodine solution.

see details below) was added as an extra component, and its mass was not considered for calculation of the solid/liquid ratio. The composition of the various formulations is shown in Table 1.

Preparation of specimens for subsequent tests was carried out following the traditional method. The activator DMT was dissolved in the liquid phase. Initiator of free radical polymerization reaction was added to the solid phase. Both phases were mixed and stirred by hand until the mixture became paste-like with a high viscosity; the mass was then placed into a poly(tetrafluoroethylene) (PTFE) mold to allow it to cure. Two molds were employed, one for cylindrical specimens (12 $\mathrm{mm}$ height, $6 \mathrm{~mm}$ diameter) and another for bar-shaped specimens $\left(50 \times 5 \times 1.5 \mathrm{~mm}^{3}\right)$. The same starch polymeric blend (SCA) was processed by conventional injection molding under optimized conditions in a Klockner-Ferromatik Desma FM20 machine to produce compact disks $(\varnothing=1 \mathrm{~cm}, e=1.5 \mathrm{~mm})$.

Two different enzyme preparations were used in this study: one is a conventional bacterial $\alpha$-amylase from Bacillus amyloliquefaciens (Optisize 160), and the other is a thermostable $\alpha$-amylase from a genetically modified strain of Bacillus licheniformis (SPEZYME FRED, $20700 \mathrm{LU} / \mathrm{mL}$ ). Both were kindly supplied by Genencor International B. V. (Leiden, The Netherlands) and provided in the liquid form. The first enzyme was used for preparation of the degradation solutions at physiological conditions, and the latter was used both in the degradation studies and also in the studies of its incorporation in the cement formulations. The various enzyme solutions were then prepared by diluting the enzyme preparations in buffer.

To perform the degradation and bioactivity tests of the developed formulations, four solutions were prepared: (a) phosphate-buffered saline (PBS) solution (0.01 M, pH 7.4), (b) PBS supplemented with $150 \mathrm{U} / \mathrm{L}^{1}$ (one enzyme unit (U) is defined as the amount of enzyme able to catalyze the hydrolysis of $\alpha$-1,4-glycosidic linkages of a soluble potato starch $(1 \%, \mathrm{w} / \mathrm{v})$ in $\mathrm{PBS}$ solution $(\mathrm{pH} 7.4)$ at $37{ }^{\circ} \mathrm{C}$ with the release of $1 \mu \mathrm{mol}$ of reducing sugar, measured as glucose, per minute) of conventional $\alpha$-amylase (PBSa), (c) PBS supplemented with 28.7 $\mathrm{LU} / \mathrm{mL}$ of thermostable $\alpha$-amylase (PBSta), and (d) simulated body fluid (SBF) solution containing $142.0 \mathrm{mM} \mathrm{Na}{ }^{+}, 5.0 \mathrm{mM} \mathrm{K}^{+}, 2.5 \mathrm{mM}$ $\mathrm{Ca}^{2+}, 1.5 \mathrm{mM} \mathrm{Mg}^{2+}, 147.8 \mathrm{mM} \mathrm{Cl}^{-}, 4.2 \mathrm{mM} \mathrm{HCO}_{3}{ }^{-}, 1.0 \mathrm{mM} \mathrm{HPO}_{4}{ }^{2+}$, and $0.5 \mathrm{mM} \mathrm{SO}_{4}^{2-}$ in distilled water and buffered with $50 \mathrm{mM}$ of tris(hydroxymethyl)amino methane (TRIS). The SBF solution has ion concentrations approximately equal to those of human blood plasma. It has been widely used for the in vitro assessment of the bioactivity of artificial materials by examining their apatite-forming ability in the fluid.

2.2. Degradation Tests. The water uptake and degradation behavior of the prepared bone cement formulations was studied over a period of 12 weeks. Cylindrical specimens were immersed in PBS, PBSa, or PBSta at a ratio of 1:15 (specimen mass:solution volume) and incubated 


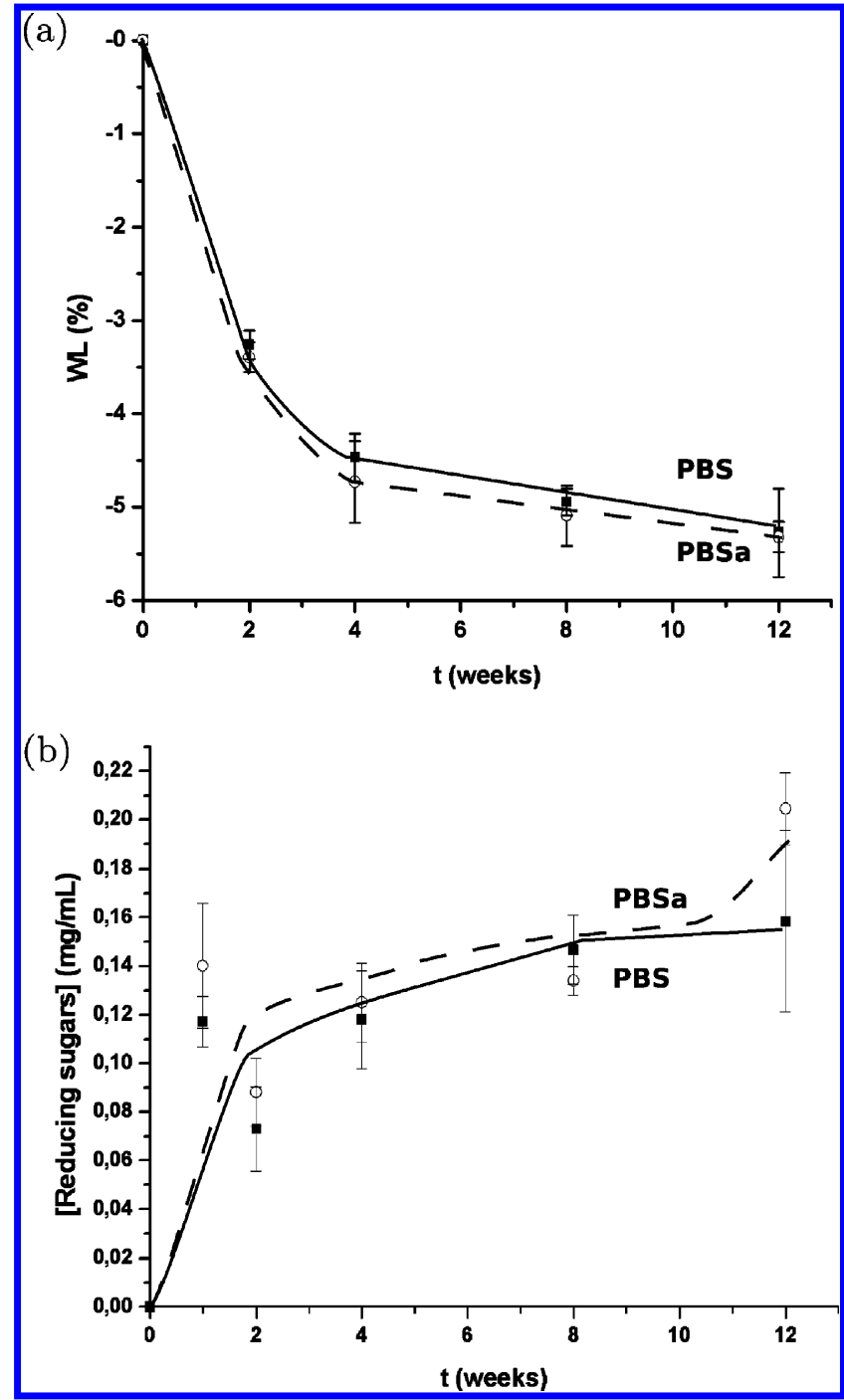

Figure 1. Degradation profile of $\mathrm{COO}$ at $37^{\circ} \mathrm{C}$ in PBS solution $(\mathrm{pH}$ 7.4) with or without $\alpha$-amylase (150 U/L) in terms of weight loss (a) and concentration of reducing sugars in solution (b). No significant differences between the two samples were found for any time period.

at $37{ }^{\circ} \mathrm{C}$ under static conditions. The specimens were removed at regular intervals, being taken out of the solution, rinsed with distilled water, blotted on filter paper to remove surface solution/water, and immediately weighed. They were then dried at controlled conditions $\left(23{ }^{\circ} \mathrm{C}, 55 \%\right.$ $\mathrm{RH})$ to constant weight in order to determine the percentages of water uptake and weight loss. The degradation solution was frozen for later analysis (determination of reducing sugars in solution).

Compact injection-molded disks of SCA controls were also incubated in PBS and PBSa at a ratio of specimen mass:solution volume equal to $1: 10$ at $37{ }^{\circ} \mathrm{C}$ for 12 weeks. At the end of the incubation period the disk specimens and solutions were treated as described for the cement formulations and the results compared with the ones obtained for the cements in the same incubation conditions.

Water uptake (WU) was calculated using the following equation

$$
\mathrm{WU}_{\mathrm{t}}=\left(\frac{m_{\mathrm{t}}-m_{\mathrm{f}}}{m_{\mathrm{f}}}\right) \times 100
$$

where $m_{\mathrm{t}}$ is the wet mass of the specimen at time $t$ (days) and $m_{\mathrm{f}}$ is the final mass after immersion and drying. The percentage of weight loss (WL) was calculated as follows

$$
\mathrm{WL}_{\mathrm{t}}=\left(\frac{m_{\mathrm{f}}-m_{0}}{m_{0}}\right) \times 100
$$

where $m_{0}$ is the initial mass prior to immersion $(t=0)$.

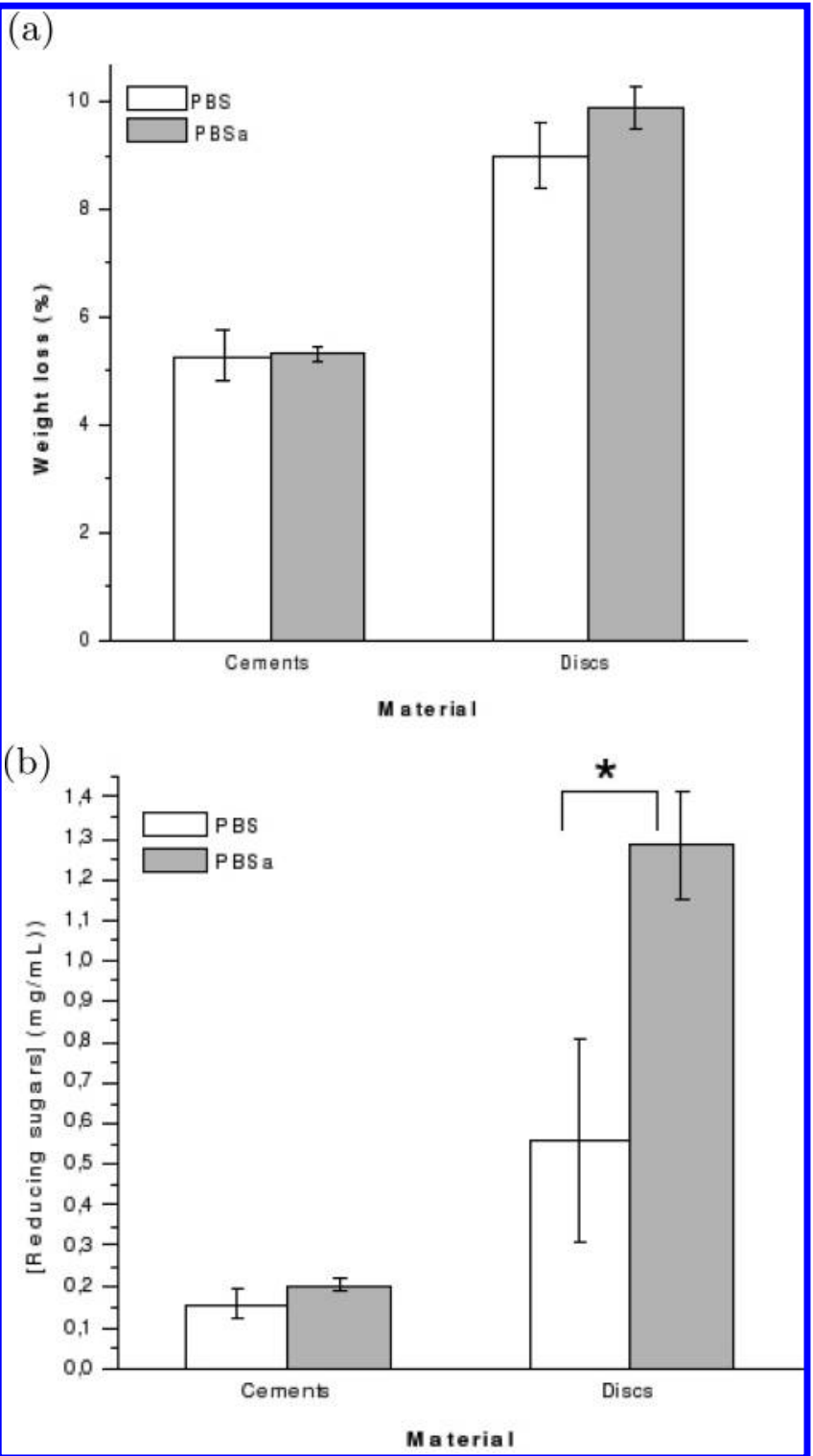

Figure 2. Comparison of the degradation rate, measured as weigh loss (a) and reducing sugars in solution (b), of SCA cements (COO) and disks after 12 weeks of incubation in PBS solution $(\mathrm{pH} 7.4)$ without or with $\alpha$-amylase $(150 \mathrm{U} / \mathrm{L})$ at $37^{\circ} \mathrm{C}$. Significant differences $(p<0.05)$ were found only for the pair marked with an asterisk $\left(^{*}\right)$.

$\alpha$-Amylase is an endo-specific enzyme which catalyzes the hydrolysis of $\alpha-1,4$-glycosidic linkages of starch to maltose and dextrins, reducing the molecular size of starch. The activity of $\alpha$-amylase can be monitored by measuring the concentration of reducing sugars released into the solution. The concentration of reducing sugars of all degradation solutions was determined using the dinitrosalicylic acid (DNS) method ${ }^{32}$ The DNS procedure is based on the reduction of the 3,5-dinitrosalicylic acid to 3-amino-5-nitrosalicylic acid under alkaline conditions, being the carbonyl group of sugars oxidized producing carboxylic groups. During this reaction there is the development of a colored complex whose intensity can be measured at $540 \mathrm{~nm}$. Quantification of reducing sugars in the degradation solutions was performed in a SpectraMax 340PC microplate spectrophotometer (Molecular Devices Corp., Sunnyvale) and using a calibration curve of standard glucose concentrations.

The morphology of the specimens after degradation was analyzed with a Leica Cambridge S360 (Leica Cambridge Ltd., Cambridge, U.K.) scanning electron microscope (SEM). Before observation, specimens were dried at room temperature for several days and gold-coated by ion sputtering (Sputter Coater SC502, Fisons Instruments, U.K.). 


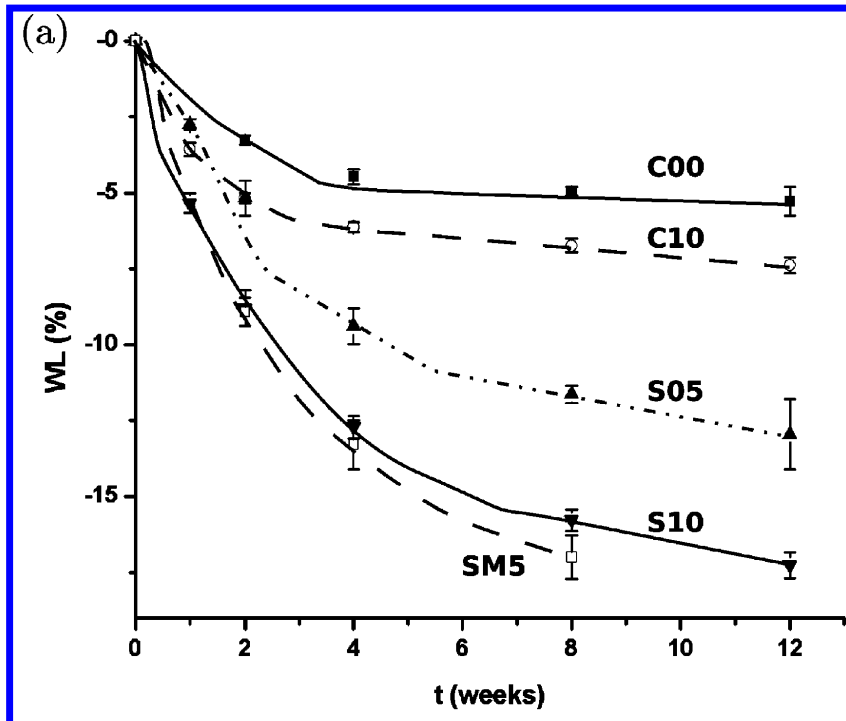

(b)

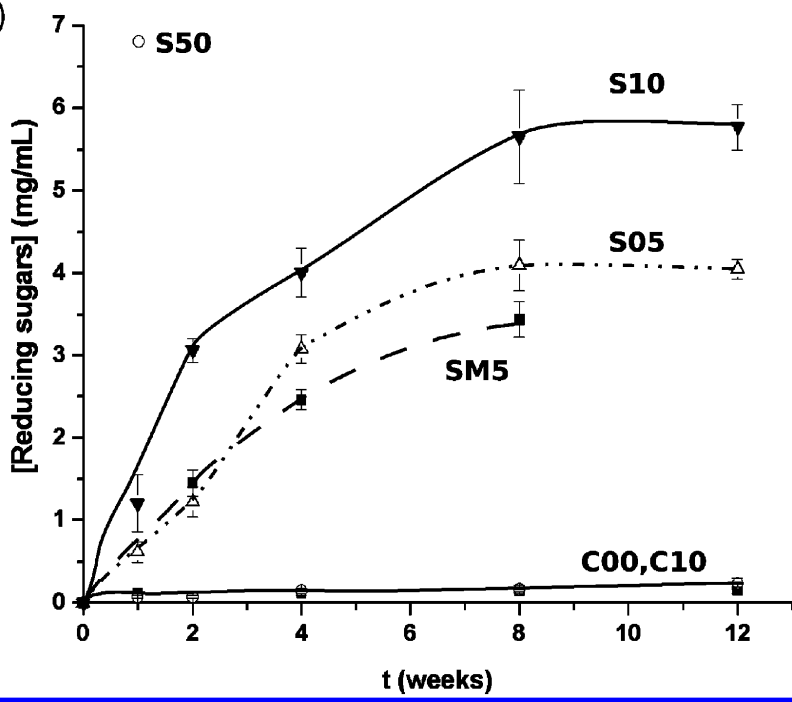

Figure 3. Degradation profile of different formulations of HDBCs in PBS in terms of weight loss (a) and concentration of reducing sugars in solution (b).

2.3. Degradation/Bioactivity Tests. For these tests bar-shaped specimens were used over a period of 16 weeks of immersion in SBF solution at $37{ }^{\circ} \mathrm{C}$. A fixed volume of $10 \mathrm{~mL}$ of SBF was used for all specimens. They were removed at regular intervals, being taken out of the solution, rinsed with distilled water, and sectioned to expose their cross-sectional area. Then the specimens were frozen at $-80{ }^{\circ} \mathrm{C}$ and freeze-dried at a condenser temperature of $-80{ }^{\circ} \mathrm{C}$ and a pressure of approximately $0.030 \mathrm{mBar}$ for $72 \mathrm{~h}$ in a Cryodos freeze-drier (Telstar Industrial, S. L., Terrassa, Spain). During the freeze-drying process no cryoprotectants were used taking into account the polymeric nature of the samples. No freezing damage, due to ice formation, is expected in this type of sample. After freeze-drying the samples were gold-coated and observed by SEM. Due to the growth of an apatite layer, WU and WL were not determined in these experiments. The concentration of reducing sugars in solution was determined as described before, and the final values were normalized considering a hypothetical mass of $0.1 \mathrm{~g}$ of starch per specimen.

The formation and growth of an apatite layer on the specimen surface was visualized by scanning electron microscopy and confirmed by energy dispersive spectroscopy (EDS), which allows the qualitative determination of the atoms present in the layer. Specimens for EDS analysis were not sputtered, while the others were gold-coated as before.

2.4. Statistical Analysis. The normality of the data was checked by visual inspection of normal probability plots for each sample studied and also by applying the Shapiro-Wilk's W test. ${ }^{33}$ For all pairs of

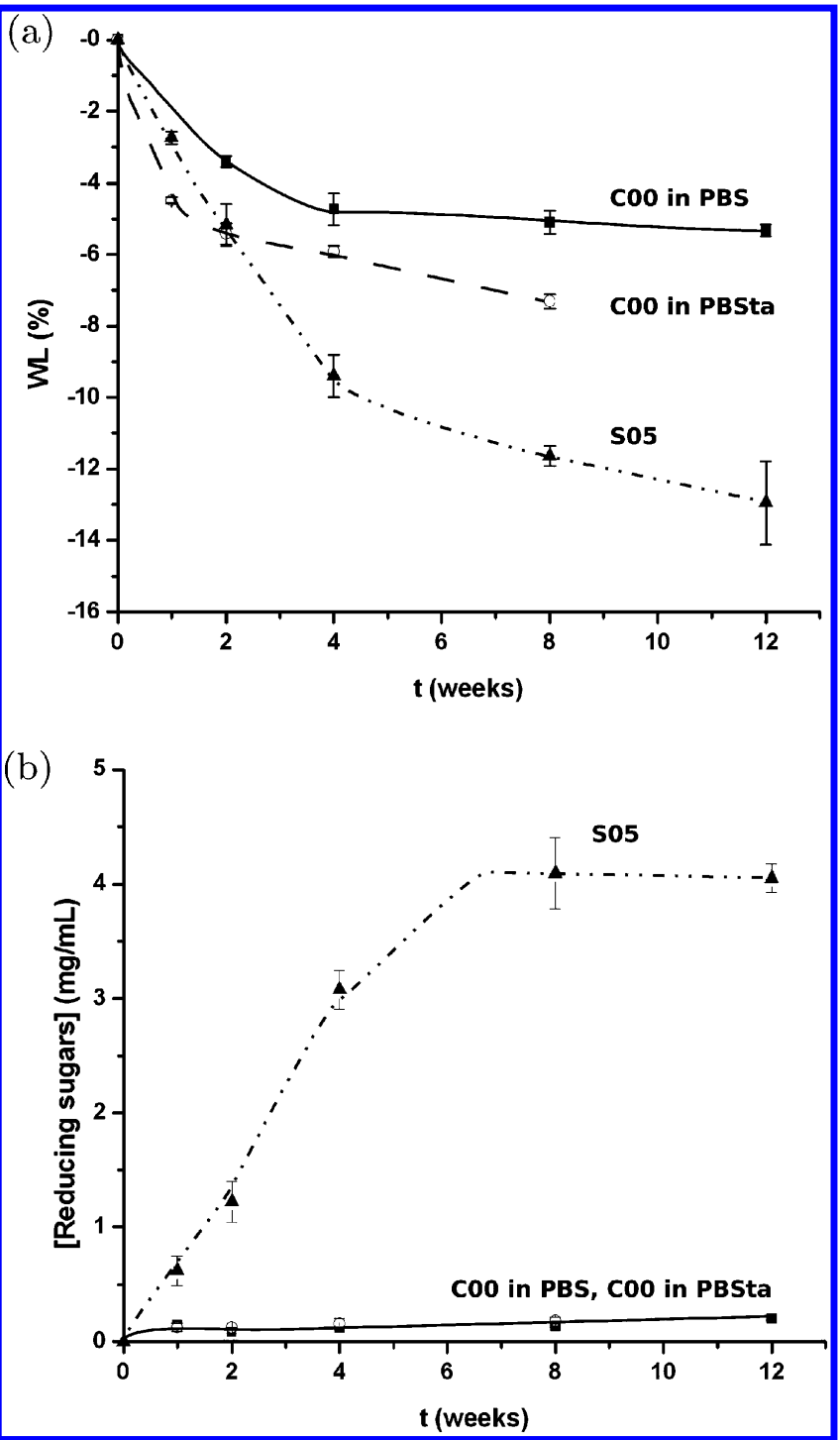

Figure 4. Degradation profile of different formulations of HDBCs in PBS or PBSta in terms of weight loss (a) and concentration of reducing sugars in solution (b).

samples with normal distribution, Student's $t$ tests for independent samples were performed to test differences among them. In a few cases the samples did not follow a normal distribution; in those cases a Mann-Whitney U test (nonparametric test) was performed. In all tests the level of significance was fixed at $p<0.05$. Therefore, throughout the following discussion the values were considered different if their difference was significant at this level. Statistical analysis was performed with Statistica 5.0 (StatSoft).

\section{Results and Discussion}

3.1. Degradation of HDBCs in Simulated Physiological Solutions Containing $\alpha$-Amylase. As Figure 1 shows there was no indication of an increased degradation of the starch contained in the bone cement when the specimens were immersed in a solution containing $\alpha$-amylase in concentration similar to those found in the human blood plasma. In this study we used a concentration of $150 \mathrm{U} / \mathrm{L}$ of $\alpha$-amylase, while it has been reported that the reference concentrations of this enzyme in serum is in the range of 46-244 U/L. ${ }^{34}$ This enzyme catalyzes the hydrolytic degradation of starch, releasing low molecular weight sugars (glucose, maltose, and other soluble oligosaccharides) to the solution as a result of the random chain scission. 


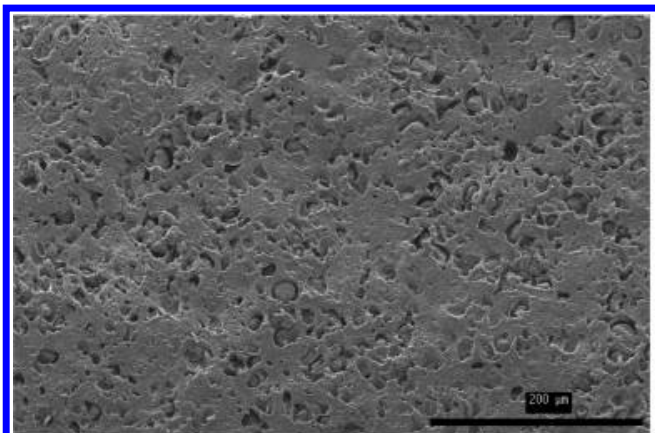

(a)

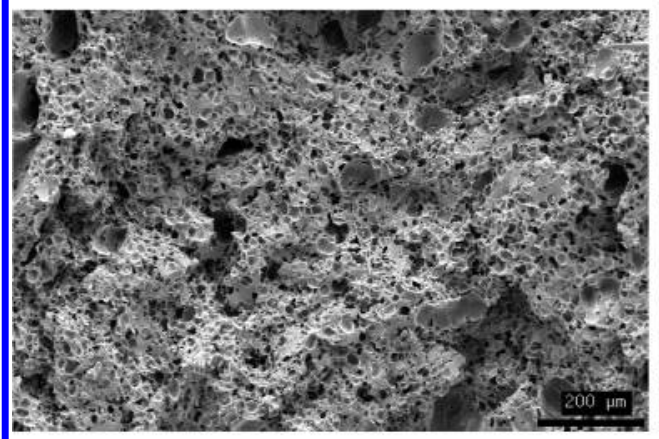

(c)

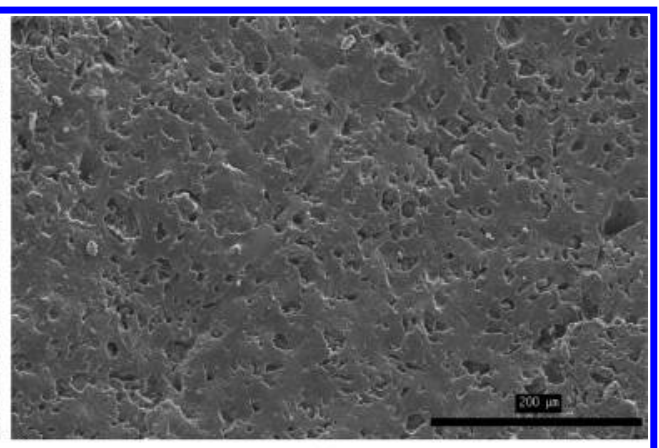

(b)

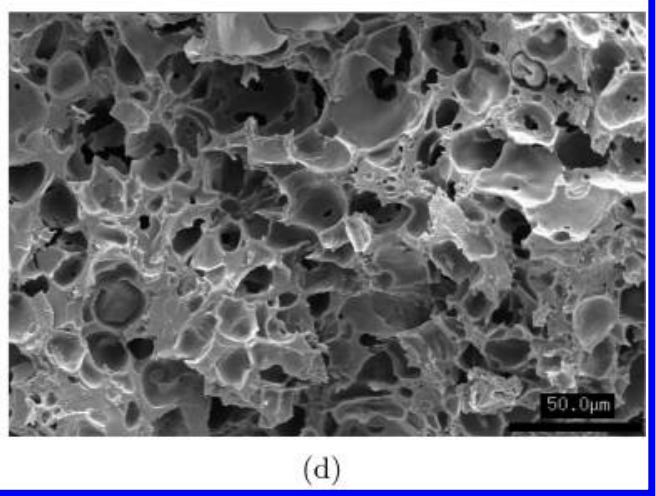

Figure 5. SEM micrographs of the cross-section of various specimens after immersion in PBS: (a) C00, 2 weeks; (b) C00, 8 weeks; (c and d) SM5, 2 weeks.

If some starch degradation was occurring, we would expect to observe higher weight loss as well as a higher concentration of reducing sugars in the solution containing $\alpha$-amylase. However, none of them occurred: none of the observed differences were significant at a 0.05 confidence level. The WL observed for both samples may be attributed to the leaching of low molecular weight molecules and plasticizers, which exist in the biodegradable blend, ${ }^{35}$ and nonpolymerized monomers or oligomers, which are soluble in water and may be released after water uptake. $^{26}$

To identify the possible reasons for this behavior, we performed similar degradation tests with injection-molded disks of pure SCA, whose results are shown in Figure 2. Although the WL was similar in samples immersed in both solutions, the concentration of reducing sugars was 2.3 times higher for the sample in contact with $\alpha$-amylase, demonstrating that in this case the $\alpha$-amylase is playing an important role in the degradation process.

The obtained results indicate that the lack of degradation of the starch present in the HDBCs may be due to the inaccessibility of the enzyme to the starch molecules. In the tested samples the starch amount available is approximately $32.5 \mathrm{wt}$ $\%$, while in the SCA disks it is $\sim 50 \mathrm{wt} \%$. Due to the proximity of the densities of all pure components (1.27 for poly-HEMA, 1.3 for cellulose acetate, and 1.4 for starch) we can hypothesize that the volume fraction resembles the weight fraction. Enzymes are proteins composed of sequences of amino acids folded into a three-dimensional structure with different levels of organization. The dimension of macromolecules (e.g., proteins with MW between 10 and $1000 \mathrm{kDa}$ ) is in the range of $2-10 \mathrm{~nm} .{ }^{36}$ The molecular weight of $\alpha$-amylase from Bacillus amyloliquefaciens (enzyme used in this study) has been reported to be $55-58 \mathrm{kDa}^{37}$. In fact, the size of the enzyme is too large to allow its diffusion through the polymeric matrix; therefore, only the starch at or close to the surface would be available for enzymatic attack. In order for the inner starch particles to be accessible, the percentage of starch in the material should be higher than the percolation threshold $\left(p_{\mathrm{c}}\right)$, that is, the minimum concentration of the dispersed medium that creates full connectivity from the bottom to the top surface. ${ }^{38}$ In such case, degradation of the starch would create a connected network of pores and voids that would allow transport of the enzyme to the interior of the material; the successive steps of starch degradation-enzyme migration would cause degradation of the total starch in the sample. Percolation threshold depends on the geometry of the medium; for a cubic lattice, $p_{\mathrm{c}}=31.17 \% .{ }^{38,39}$ Moreover, the accessibility of the dispersed phase depends also on the homogeneity of the dispersion and the size of the particles: if there is aggregation or a large distribution of particle sizes, the accessibility will not follow that indicated by percolation theory. ${ }^{39}$ Nonetheless, as an example of the importance of the amount of degradable component, Wool et al. ${ }^{38}$ found that by increasing the starch concentration from 20 to $35 \mathrm{vol} \%$ in a polyethylene matrix the aerobic biodegradation of starch increased from 7 to 75 wt $\%$ after 20 days. Therefore, one can conclude that the volume fraction of starch in HDBCs is insufficient to create percolation and, as a consequence, a very low amount of the starch will be degraded, as in fact happened. If a higher amount was used, the degradation extent would have been higher, as the results indicate for pure SCA (degradation tests with disks). Despite the different geometries of cements and disk specimens impede a direct and quantitative comparison between them, Figure $2 b$ seems to confirm this assumption since the amount of RS released to the solution was considerably higher for the SCA disks than for the SCA-based cements. Therefore, to allow degradation of all the starch present in HDBCs, these should either incorporate a thermostable enzyme in their formulation or contain a higher amount of starch, well above the $p_{\mathrm{c}}$. In the following section we report the results of the former approach, while the latter will be presented in a future paper.

3.2. Effect of $\alpha$-Amylase Incorporation on the Degradation Behavior of the Cement Formulations. The incorporation of 


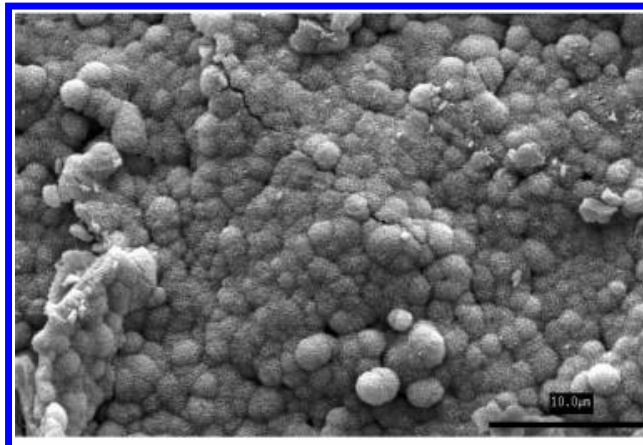

(a)

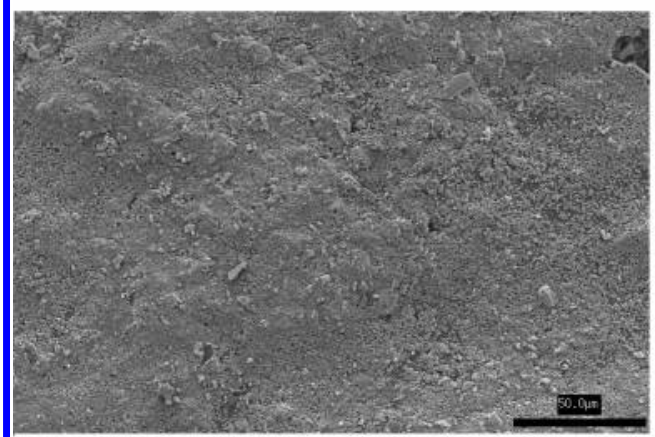

(c)

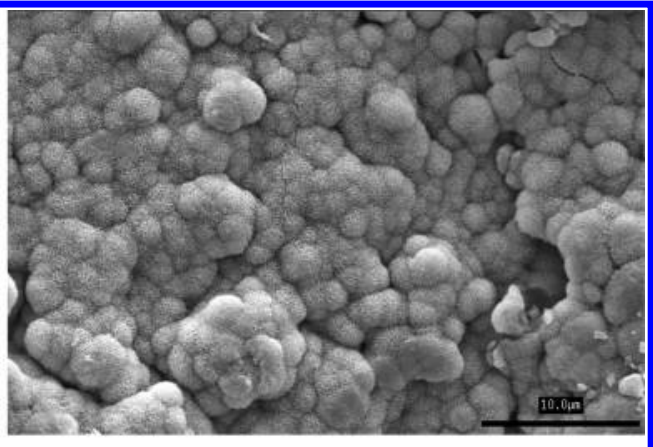

(b)

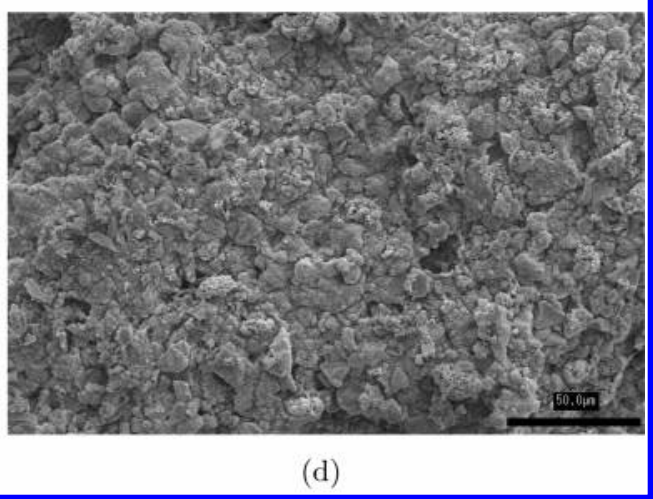

Figure 6. SEM micrographs of the surface of specimens after immersion in SBF: (a) BC0, 4 weeks; (b) B30, 1 week; (c) BS5, 2 weeks; (d) BS5, 12 weeks.

different amounts of $\alpha$-amylase was performed in order to control the degradation rate of starch in the formulations. As Figure 3 shows, the presence of enzyme has a strong influence on the degradation of the samples; even after 1 week the concentration of reducing sugars for sample S50 was 58 times higher than that for the control $(\mathrm{CO0})$. Although the trend (regarding the influence of increasing amounts of $\alpha$-amylase) is the same for both weight loss and reducing sugars results, the effect of adding the enzyme is much stronger for the amount of reducing sugars than for WL: RS is related to the number of molecules released to the solution, while WL is related to their total mass. Therefore, one would expect a stronger influence of the enzyme on the results of RS since $\alpha$-amylase catalyzes the random degradation of starch molecules to glucose or other soluble maltooligosaccharides. However, at early stages of degradation, only small molecular weight fragments are released and therefore no significant changes in the total mass of the material/specimen were observed. On the other hand, the soluble low molecular weight sugars released into the solution are more accessible for further enzyme hydrolysis (when compared with the high molecular weight of starch molecule), which also contribute to the increase of reducing sugars in solution. Regarding WL, it is clear that there is some influence of the addition of an extra amount of liquids: in fact, the difference between $\mathrm{C} 10$ and $\mathrm{C} 00$ is approximately constant and close to the amount of water added to $\mathrm{C} 10(\sim 2.4 \mathrm{wt} \%)$. Therefore, one could hypothesize that the maximum contribution to the WL of the water present in the enzymatic solution would be around this value since, for example, $0.10 \mathrm{~mL}$ of the solution was added to sample S10. In terms of RS, as expected, the water had no effect; the degradation of starch can therefore be attributed solely to the presence of $\alpha$-amylase.

Comparing S10 formulation with $\mathrm{C} 10$, we observed that after 12 weeks only about $10 \%$ of the WL may be attributable to starch degradation (that is, $\mathrm{WL}_{\mathrm{S} 10}-\mathrm{WL}_{\mathrm{C} 10}$ ) due to the hydrolytic effect of the enzyme. This is much lower than the quantity

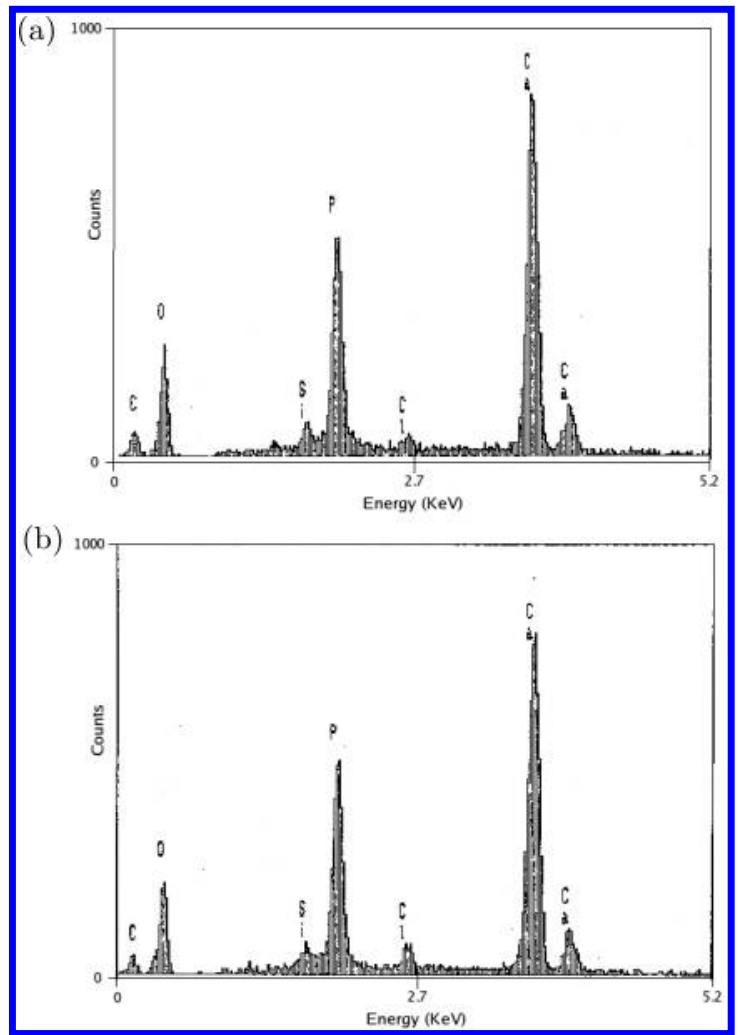

Figure 7. EDS spectra of the surface of BC0 (a) and B15 (b) after 2 weeks in SBF.

of starch in the formulation ( $232.5 \mathrm{wt} \%)$ and may demonstrate, once again, that the lack of full connectivity among starch sites avoids complete degradation of this material. To clarify this point and avoid any misunderstanding related to the different $\alpha$-amylases used in parts A and B of this study (conventional $\alpha$-amylase in part $\mathrm{A}$ and thermostable one in $\mathrm{B}$ ), we performed a final test comparing S05, C00, and C00 immersed in PBS 


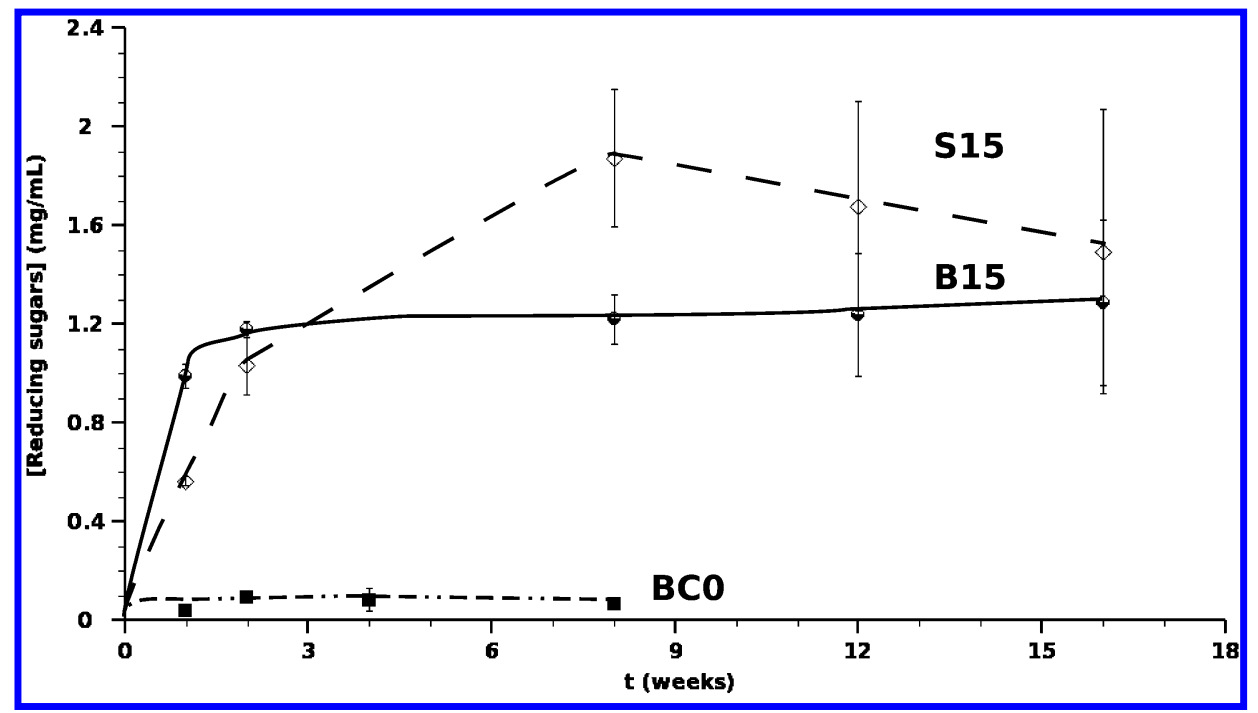

Figure 8. Degradation profile (in terms of concentration of reducing sugars in solution) of different HDBC formulations in SBF. Significant differences $(p<0.05)$ were as follows: between B15 and S15 at 1 and 8 weeks; between BC0 and S15 at all time periods; between BC0 and B15 at all time periods.

containing exactly the same amount of enzyme as that added to $\mathrm{S} 05$ (that is, $28.7 \mathrm{LU} / \mathrm{mL}$ ). The results are presented in Figure 4 and definitively demonstrate the lack of availability of starch to the $\alpha$-amylase present in solution. For the current systems the enzyme must be added to the formulation to promote starch degradation. This is a very important conclusion.

Besides varying the amount of added enzyme, another way of controlling the degradation of starch can be achieved by changing the hydrophilicity of the formulation. This is also displayed in Figure 3. The RS for SM5, after 4 weeks, was always significantly lower than that for the more hydrophilic counterpart (S05). SM5 is more hydrophobic due to addition of a hydrophobic monomer (MMA), which amounts to 66.7 mol $\%$ of the monomer mixture. On the other hand, WL was higher, which was not surprising since we have already shown ${ }^{26}$ that this may happen for such systems; the probable causes are a different conformation of acrylic chains and a higher amount of unpolymerized monomer due to the different composition of the monomer mixtures.

As a result of the enzymatic degradation, one should expect the appearance of pores and voids in the volume previously occupied by the starch (Figure 5). After 8 weeks C00 remained basically a dense specimen with few shallow and isolated (not connected) pores. For the specimens containing $\alpha$-amylase, a completely different scenario was observed: the SEM micrographs of their cross sections showed a homogeneously distributed porosity, which presented a certain degree of connectivity. The pore size was not very high (since they were limited by the particle size of SCA, that is $125 \mu \mathrm{m}$ ) and had a round shape, confirming that, in general, they were formed by degradation of a particulate filler (the starch present in SCA) while the structure was kept by the inert acrylic matrix. The low level of degradation is confirmed; it is clear in the micrographs that the pores represent a low amount of the total area, the majority of which is occupied by the matrix and undegraded starch. Even with longer degradation periods the total pore volume was not sufficient for achieving full connectivity. Clearly, a higher amount of starch is needed to that aim being achieved.

3.3. Evaluation of the Simultaneous Bioactivity/Degradation Phenomena in a Simulated Body Fluid (SBF). The main purpose of the biodegradable component of the bone cement is to allow space for bone growth inside the cement and not only on the surface as occurs with all other bioactive cement formulations. Therefore, we wanted to know if the presence and activity of the enzyme disturbs apatite formation and growth (and vice versa, that is, if the apatite growth alters the degradation rate) and if the apatite is able to grow inside the pores formed during degradation.

Figure 6 compares the apatite nucleated on the surface of specimens with and without enzyme. Both the morphology and size of the apatite crystals which constitute the layer are very similar, almost identical. Moreover, as Figure 6c shows, the layer was dispersed along the entire surface and for longer immersion times (Figure 6d) the area occupied by the layer and its thickness increased. In terms of the composition of the layer, at least qualitatively, they are also identical, as shown in Figure 7. Both layers are composed only of $\mathrm{Ca}$ and $\mathrm{P}$, with residual amounts of $\mathrm{Si}$ (present in the glass under the layer) and $\mathrm{Cl}$ (precipitated from the solution).

On the other hand, the presence of the glass and the apatite layer seemed to change the degradation rate of the cements (Figure 8). Using a similar system (which contained a different bioactive glass) we have already shown ${ }^{7}$ that the WL (in normal saline solutions) of cements containing glass, after 1 week, can be up to 2.5 times higher than the WL for systems without glass. This would create a higher volume of voids (especially on the glass-polymer interface), allowing for easier diffusion of the enzyme to the starch sites; the degradation rate of starch would therefore be higher for B15 in the first week of immersion. However, at later stages (up to 8 weeks) the trend was inverted; this was not surprising (given the discussion outlined in the previous section) since the total amount of starch in B15 was one-half that in S15. Starch was present in a concentration even further from the percolation threshold; therefore, the amount to be degraded was lower than in S15. Indeed, after 2 weeks there seemed to be stagnation in the degradation with the levels of $\mathrm{RS}$ reaching a plateau. Finally, for long degradation times (more than 8 weeks) there were no significant differences between both samples, although the averages were always higher for S15. The longer the degradation period, the more inhomogeneous the degradation profile (noticeable as a strong increase in the standard deviation) with large variations in the amount of specimens in the same period. In our opinion, this was a result of the inaccessibility of all the starch to the enzyme; therefore, in different specimens the distribution of starch and enzyme in 


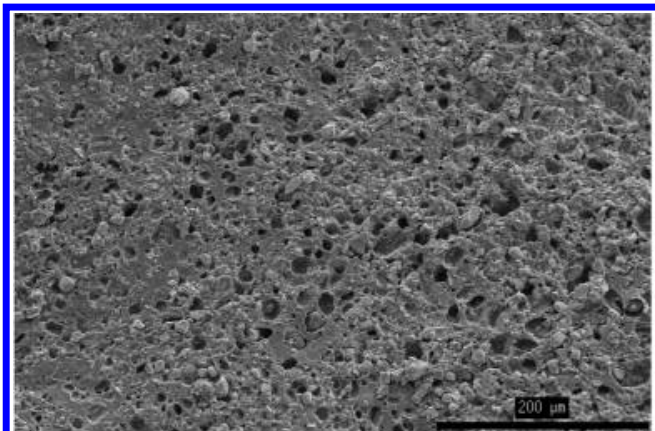

(a)

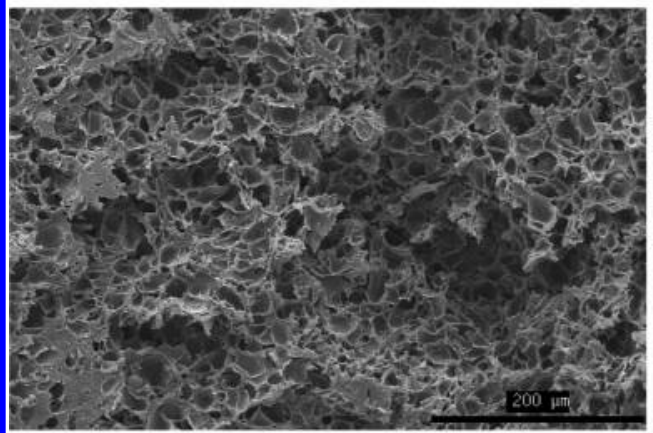

(c)

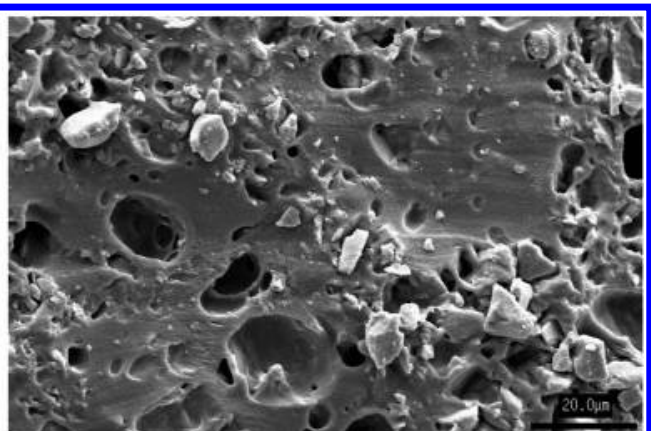

(b)

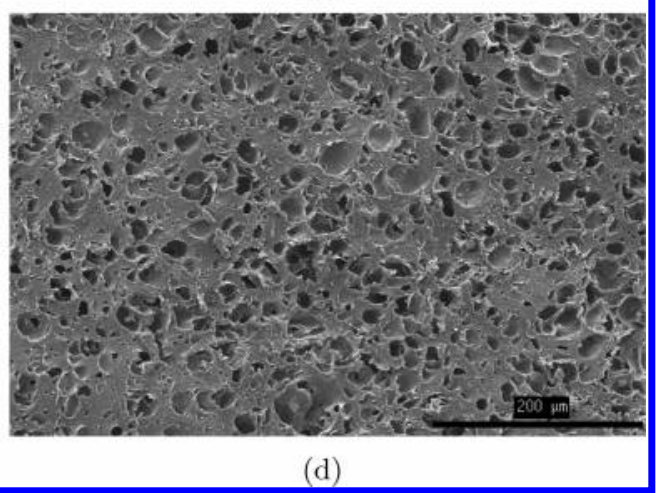

(d)

Figure 9. SEM micrographs showing the formation of porosity in (a) B15 after 16 weeks of immersion, (b) B30 after 8 weeks of immersion, (c and d) $\mathrm{S} 15$ after 8 weeks of immersion. All specimens immersed in SBF at $37^{\circ} \mathrm{C}$.

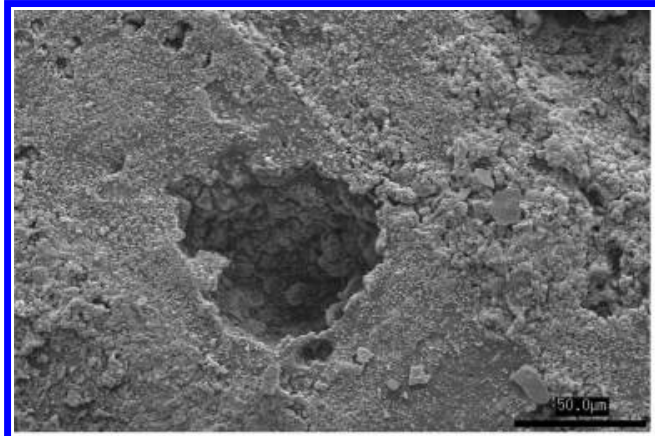

(a)

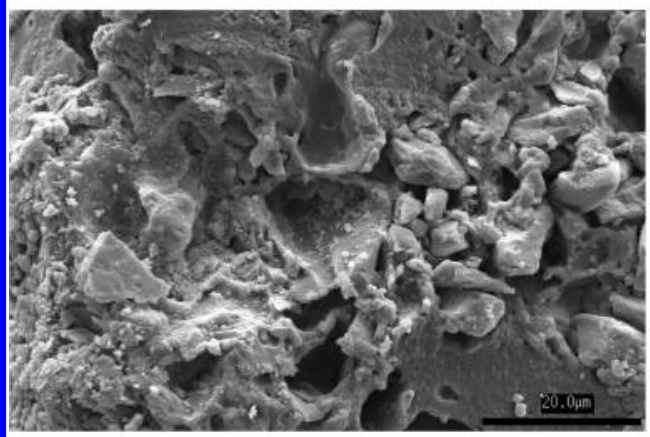

(c)

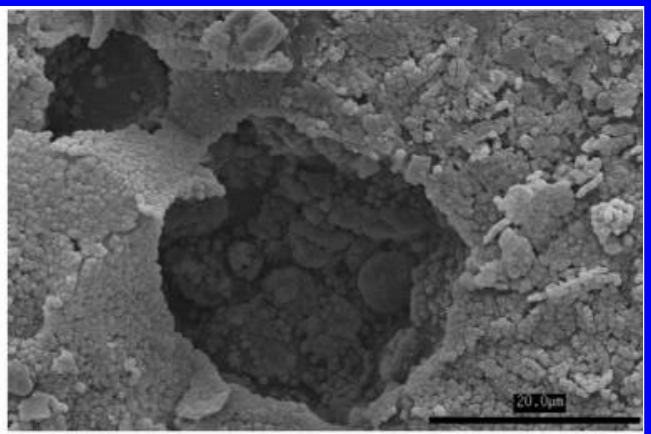

(b)

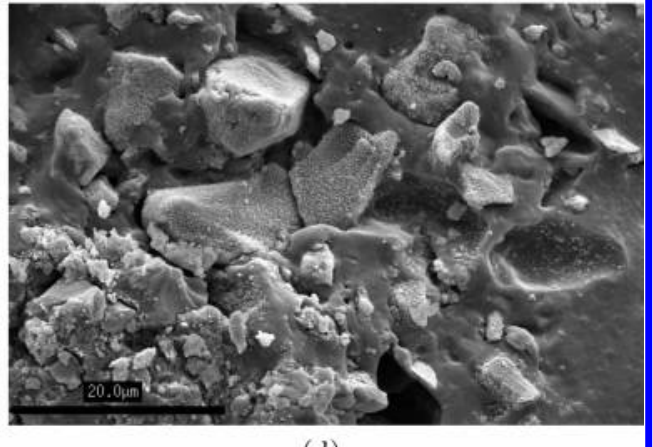

(d)

Figure 10. Formation of calcium phosphate on surface pore walls of B15 after 1 (a) and 16 (b) weeks of immersion. Spreading of calcium phosphate nuclei to inner pores near the surface in B30 after 2 weeks of immersion (c) or to pores near glass particles (d). All specimens immersed in SBF at $37^{\circ} \mathrm{C}$.

the space was different, and slight differences could make more (or less) starch available to the enzyme, markedly changing the amount degraded.

The above discussion is corroborated by the SEM micrographs (Figure 9). Even after 16 weeks of immersion the porosity in B15 was low and with no connectivity (Figure 9a). One may assume that the $\alpha$-amylase had access only to the starch in its immediate vicinity and/or to the starch surrounding glass particles, where the weak interface provided a higher surface area. Although specific techniques (microcomputed tomography, mercury intrusion porosimetry) were not employed to determine the connectivity, Figure $9 \mathrm{~b}$ shows in more detail the closeness and apparent lack of connectivity of the pores. A completely different picture was observed for S15 (Figure 9b), with a much higher number of pores, with those well connected among them. However, as outlined above, there was a large 
heterogeneity among specimens (or among different regions of a same specimen); Figure 9d shows a different pattern of porosity. As we were working very close to the percolation threshold of a 3D structure, small inhomogeneities of the local distribution of both the starch and the $\alpha$-amylase could have a strong effect on the degradation profile and on the porosity distribution.

Given the low level of starch degradation in B15 and, consequently, the lack of pore connectivity, our aim of observing apatite growth inside inner pores was not achieved. Obviously, pores must be interconnected for spreading of the apatite layer to the interior of the material. However, we observed some interesting findings. Figure $10 \mathrm{a}$ and $\mathrm{b}$ shows that at early stages of apatite formation ( 1 week) nuclei were already being formed on the walls of surface pores. After 16 weeks a dense layer had been formed without covering the pores; instead, the apatite layer was also found on the pores. In an attempt to generate more pores at the early stages of degradation, we used a formulation with an increased amount of enzyme (B30) and observed that apatite nuclei did form on the walls of inner pores near the surface (Figure 10c), meaning that it is indeed possible, if adequate pore connectivity is achieved, to nucleate apatite inside the cements. Moreover, as seen in the right-hand side of Figure 10c and in Figure 10d, even if the pores were closed, not connected, few apatite nuclei were observed on the walls of those near glass particles (as well as on the surface of the glass particles themselves). It seems that the high values of WU of these systems, the pores formed during degradation, and the voids around glass particles formed due to water attack to the interface ${ }^{7}$ were contributing to the creation of a microenvironment inside the material that was simulating the one existing at the external surface, being propitious to the nucleation of an apatite layer. This is a promising indication that bone ingrowth inside the material, when implanted, might be possible.

\section{Conclusions}

In this work we have shown that HDBCs are materials susceptible to enzymatic degradation, catalyzed by $\alpha$-amylase. The rate of degradation can be easily tailored by means of proper choice of the hydrophilicity of the formulation or the amount of thermostable $\alpha$-amylase added to the composition. The total amount of starch in the formulation proved to be a more important factor than the quantity of enzyme since a minimum concentration of starch is required to provide full connectivity among the pores. With our current formulation the amount of starch was below this percolation threshold; therefore, full connectivity could not be achieved. Starch amounts can, of course, still be increased further in future studies, and in such case, even the $\alpha$-amylase present in the human blood plasma might be enough to provoke starch degradation, as it occurred with injection-molded SCA disks, which contain more starch than HDBCs.

This system was also able to promote the nucleation and growth of an apatite layer on the surface and, at a lower extent, on the walls of superficial and inner pores. This is an important prerequisite for successful application of bone cements since it indicates that, in vivo and with a higher degree of connectivity, bone will be able to grow inside the pores formed during degradation. This will surely increase the interfacial strength cement-bone and make the cement more stable, solving one of the most important causes of failure in hip replacements. For better performance of the HDBCs, an alternative method to promote bioactivity should be employed since the glass reduced the propensity of the starch to be degraded and, as consequence, the possibility of forming a connected network of pores.

Acknowledgment. L.F.B. acknowledges the Fundação Coordenação de Aperfeiçoamento de Pessoal do Ensino Superior (CAPES-Brasília, Brazil) for the Ph.D. grant. H.S.A. thanks the Portuguese Foundation for Science and Technology (FCT) for providing her a postdoctoral scholarship (SFRH/BPD/5744/ 2001). This work was partially supported by FCT through funds from the POCTI and/or FEDER programs.

\section{References and Notes}

(1) Malchau, H.; Herberts, P. Book of Abstracts; Annual Meeting of the American Academy of Orthopaedic Surgeons, New Orleans, 1998; Vol. 65.

(2) Park, J. B. In The biomedical engineering handbook; Bronzino, J. D., Ed.; CRC Press: Boca Raton, 2000; url http://www.engnetbase.com/ejournals/books/book_km.asp?id=402.

(3) Liu, Y. K.; Njus, G. O.; Park, J. B.; Stienstra, D. J. Biomed. Mater. Res. 1987, 21, 247-261.

(4) Henrich, D. E.; Cram, A. E.; Park, J. B.; Lui, Y. K.; Reddi, H. J. Biomed. Mater. Res. 1993, 27, 277-280.

(5) Downes, S.; Wood, D. J.; Malcolm, A. J.; Ali, S. Y. Clin. Orthop. Relat. Res. 1990, 252, 294-298.

(6) Goodwin, C. J.; Braden, M.; Downes, S.; Marshall, N. J. J. Biomed. Mater. Res. 1997, 34, 47-55.

(7) Boesel, L. F.; Fernandes, M. H. V.; Reis, R. L. J. Biomed. Mater. Res. B 2004, 70B, 368-377.

(8) Shinzato, S.; Kobayashi, M.; Mousa, W. F.; Kamimura, M.; Neo, M.; Kitamura, Y.; Kokubo, T.; Nakamura, T. J.Biomed.Mater. Res 2000, 51, 258-272.

(9) Mousa, W. F.; Fujita, H.; Ido, K.; Neo, M.; Kobayashi, M.; Zeineldin, I. A.; Matsushita, M.; Nakamura, T. J.Biomed.Mater. Res.: Appl. Biomater. 1999, 48, 726-733.

(10) Sogal, A.; Hulbert, S. F. Proceedings of the International Symposium on Ceramics in Medicine, Kyoto, 1992; Vol. 5, pp 213-224.

(11) Dalby, M. J.; di Silvio, L.; Harper, E. J.; Bonfield, W. J. Mater. Sci.: Mater. Med. 1999, 10, 793-796.

(12) Harper, E. J.; Behiri, J. C.; Bonfield, W. J. Mater. Sci.: Mater. Med 1995, 6, 799-803

(13) Shinzato, S.; Kobayashi, M.; Mousa, W. F.; Kamimura, M.; Neo, M.; Choju, K.; Kokubo, T.; Nakamura, T. J.Biomed. Mater. Res.: Appl. Biomater. 2000, 53, 51-61.

(14) Kobayashi, M.; Nakamura, T.; Okada, Y.; Fukumoto, A.; Furukawa, T.; Kato, H.; Kokubo, T.; Kikutani, T. J.Biomed. Mater. Res. 1998, $42,223-237$.

(15) Gomes, M. E.; Reis, R. L.; Mikos, A. G. In Biodegradable systems in tissue engineering and regenerative medicine; Reis, R. L., San Román, J., Eds.; CRC Press: Boca Raton, 2004; pp 29-38.

(16) Taguchi, T.; Kishida, A.; Akashi, M. Chem. Lett. 1998, 8, 711712.

(17) Pashkuleva, I.; Marques, A. P.; Vaz, F.; Reis, R. L. J. Mater. Sci.: Mater. Med. 2005, 116, 81-92.

(18) Gomes, M. E.; Sikavitsas, V. I.; Behravesh, E.; Reis, R. L.; Mikos, A. G. J. Biomed. Mater. Res. A 2003, 67A, 87-95.

(19) Silva, G. A.; Costa, F. J.; Neves, N. M.; Coutinho, O. P.; Dias, A. C. P.; Reis, R. L. J. Biomed. Mater. Res. A 2005, 73A, 234-243.

(20) Elvira, C.; Mano, J. F.; San Román, J.; Reis, R. L. Biomaterials 2002, 23, 1955-1966.

(21) Baran, E. T.; Mano, J. F.; Reis, R. L. J. Mater. Sci.: Mater. Med. 2004, 15, 759-765.

(22) Reis, R. L.; Cunha, A. M.; Allan, P. S.; Bevis, M. J. Adv Polvm. Technol. 1997, 16, 263-277.

(23) Sousa, R. A.; Kalay, G.; Reis, R. L.; Cunha, A. M.; Bevis, M. J. J. Appl. Polvm. Sci. 2000, 77, 1303-1315.

(24) Pereira, C. S.; Cunha, A. M.; Reis, R. L.; Vázquez, B.; San Román, J. J. Mater. Sci.: Mater. Med. 1998, 9, 825-833.

(25) Espígares, I.; Elvira, C.; Mano, J. F.; Vázquez, B.; San Román, J.; Reis, R. L. Biomaterials 2003, 23, 1883-1895.

(26) Boesel, L. F.; Mano, J. F.; Reis, R. L. J. Mater. Sci.: Mater. Med. 2004, 15, 73-83.

(27) Boesel, L. F.; Reis, R. L. J. Mater. Sci.: Mater. Med. 2004, 15, 503-506.

(28) Goldbart, R.; Traitel, T.; Lapidot, S.; Kost, J. Polym. Adv. Technol. 2002, 13, 1006-1018 
(29) Yilmaz, G.; Ongen, G.; Jongboom, R.; Feil, H.; van Dijk, C.; Hennink, W. Biomacromolecules 2002, 3, 305-311.

(30) Dumoulin, Y.; Cartilier, L.; Mateescu, M. J. Controlled Release 1999, $60,161-167$.

(31) Tuovinen, L.; Peltonen, S.; Liikola, M.; Hotakainen, M.; LahtelaKakkonen, M.; Poso, A.; Jarvinen, K. Biomaterials 2004, 25, 43554362 .

(32) Ghose, T. K. Pure Appl. Chem. 1987, 59, 257-268.

(33) Statsoft, Inc. Electronic statistics textbook; Statsoft: Tulsa, OK, 2006; url http://www.statsoft.com/textbook/stathome.html.

(34) Junge, W.; Troge, B.; Klein, G.; Poppe, W.; Gerber, M. Clin. Biochem. 1989, 22, 109-114.
(35) Vaz, C. M.; Reis, R. L.; Cunha, A. M. Mater. Res. Innovations 2001, 4, 375-380.

(36) Bailey, J. E.; Ollis, D. F. Biochemical Engineering Fundamentals, 2nd ed.; McGraw-Hill: Singapore, 1986.

(37) Takkinen, K.; Pettersson, R.; Kalkkinen, N.; Palva, I.; Soderlund, H.; Kaariainen, L. J. Biol. Chem. 1983, 258, 1007-1013.

(38) Wool, R. P.; Raghavan, D.; Wagner, G. C.; Billieux, S. J. Appl. Polvm. Sci. 2000, 77, 1643-1657.

(39) Wool, R. P. Polymer Interfaces: Structure and strength; Hanser: München, Germany, 1995; Chapter 4.

BM060387J 